\title{
Influence of the Halogen and Organometallic Function in a KCTP (co)polymerization
}

\author{
Tine Hardeman ${ }^{1}$, Jasmine De Becker ${ }^{1}$, Guy Koeckelberghs ${ }^{1}$ \\ ${ }^{1}$ Laboratory for Polymer Synthesis, Division of Polymer Chemistry \& Materials, KU Leuven, \\ Celestijnenlaan 200F, 3001 Heverlee (Leuven), Belgium \\ Correspondence to: Guy Koeckelberghs (E-mail: guy.koeckelberghs@chem.kuleuven.be) \\ ((Additional Supporting Information may be found in the online version of this article.))
}

\begin{abstract}
The effect of changing the halogen and the organometallic function in a Kumada Catalyst Transfer Polycondensation (KCTP) of poly(3-alkylthiophene)s (P3AT) is investigated. On one hand, the bromine substituent is replaced with chlorine in the commonly used 2-bromo-5-chloromagnesio-3-

hexylthiophene. The effect on the homopolymerization is clear, since the stickiness decreases remarkably, but copolymerizations are hardly affected when a chlorinated monomer is used. Second, the option of changing the organometallic function is considered. Because also organozinc compounds provide a controlled P3AT polymerization with $\mathrm{Ni}(\mathrm{dppp}) \mathrm{Cl}_{2}$, but are less reactive than organomagnesium compounds, the effect of using zinc in one monomer during a copolymerization is investigated. However, it is found that the organometallic functions exchange during mixing of the monomers. Consequently, no effect is observed during copolymerizations.
\end{abstract}

KEYWORDS: Poly(thiophene), KCTP, controlled polymerization, halogen, Negishi, Kumada

\section{INTRODUCTION}

After the discovery of the controlled nature of the poly(3-hexylthiophene) (P3HT) polymerization by McCullough ${ }^{1}$ and Yokozawa ${ }^{2}$, the field of conjugated polymers evolved tremendously. While the KCTP mechanism is used to polymerize a wide variety of monomers, the halogen and organometallic function on these monomers are almost consistently bromine and chloromagnesio, respectively. ${ }^{3-10}$ Nevertheless, changing these functions can affect the (co)polymerization of the monomers. Concerning the halogen, replacing the monomer with its chlorinated analogue can be very interesting, as already noticed by the research group of Mori. ${ }^{11}$ By combining the use of a chlorine atom on the 2-position and keeping a hydrogen on the 5-position (instead of iodine), which can be converted using the KnochelHauser base, they are able to significantly lower the mass loss during the polymerization. It is also observed that the polymerization of chlorosubstituted thiophene works using $\mathrm{Ni}(\mathrm{dppp}) \mathrm{Cl}_{2}$ (dppp = 1,3-bis(diphenylphosphino) propane), but that a $\mathrm{Ni}$ catalyst bearing a $\mathrm{N}$-heterocyclic carbene ligand ([1,3-bis(2,6-diisopropylphenyl) imidazol-2-ylidene] triphenylphosphine nickel(II) dichloride; $\mathrm{NiCl}_{2}\left(\mathrm{PPh}_{3}\right)$ IPr) is more effective. However, the influence of changing the halogen on parameters such as the stickiness, the ratedetermining step and the behavior in copolymerizations is not yet investigated. Nevertheless, the increased electronegativity of chlorine compared to bromine and stronger C$\mathrm{Cl}$ bond can have an influence on these properties. 
With respect to the organometallic function, one can consider changing the organomagnesium with an organozinc functionality. As was already shown in the original research article of Sheina et al., a controlled polymerization of $\mathrm{P} 3 \mathrm{HT}$ is also obtained using the organozinc monomer and $\mathrm{Ni}(\mathrm{dppp}) \mathrm{Cl}_{2}$ catalyst. ${ }^{1}$ Later on, Higashihara et al. used zincate complexes to obtain a controlled synthesis of P3HT with higher tolerance towards protic impurities. ${ }^{12,13}$ However, organomagnesium compounds are often preferred because of their ease of formation via a GRIM reaction. Nevertheless, organozinc compounds also offer interesting opportunities in copolymerizations with organomagnesium compounds. Because they have a different reactivity, but can be copolymerized with the same catalyst, the possibility is considered to tune the copolymerization of two monomers by appropriately assigning the different organometallic functions. This could either be used to obtain a more random copolymerization of monomers with different reactivity ratios, or alternatively to obtain gradient copolymers from otherwise randomly copolymerizing monomers.

\section{RESULTS AND DISCUSSION}

\section{Effect of changing the halogen}

\section{Homopolymerization}

The homopolymerization of 2-chloro-5chloromagnesio-3-hexylthiophene is performed both with $\mathrm{Ni}(\mathrm{dppp}) \mathrm{Cl}_{2}$ and $\mathrm{NiCl}_{2}\left(\mathrm{PPh}_{3}\right) \mathrm{IPr}$, since Tamba et al. found this catalyst to be very efficient for the polymerization of a chlorosubstituted monomer (Scheme 1). ${ }^{11}$ As a reference, also the 'regular' bromo-substituted monomer is polymerized using the same procedures.
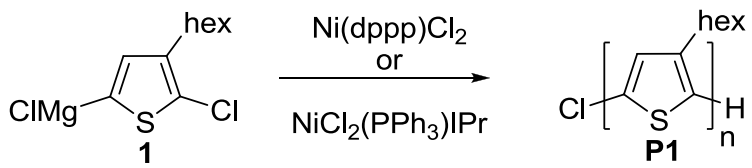

SCHEME 1 Synthesis of P3HT, starting from 2chloro-5-chloromagnesio-3-hexylthiophene.
The end-group analyses via ${ }^{1} \mathrm{H}-\mathrm{NMR}$, low dispersities observed with GPC and the good agreement between the aimed and obtained degree of polymerization support the statement that these are indeed controlled polymerizations (SI).

\section{Stickiness}

The concept of stickiness was first introduced by Tkachov et al. ${ }^{14}$ and determines - together with statistics - the amount of unidirectional growth during a KCTP. After reductive elimination (RE), the catalyst can move in two directions: towards the bromothienyl end group, or towards an internal thiophene ring. These are not equivalent because of the presence of bromine. As a consequence, it is assumed that hopping towards the bromothienyl group is preferred. This preference is described as the stickiness $\delta$ and is defined by the following equation.

$P(N)=N^{\delta-1}$

In this equation, $\mathrm{P}$ is the likeliness of unidirectional growth and $\mathrm{N}$ is the degree of polymerization. The stickiness only has an effect on the site near the chain end, otherwise the walk of the catalyst over the polymer chain is random. A value for $\delta$ close to 1 means that almost exclusively unidirectional growth occurs. To determine $\delta$, the position of the tail-to-tail coupling is used. In a KCTP polymerization, one tail-to-tail coupling is initially formed when a $\mathrm{Ni}(\mathrm{II})$-salt is used. If the polymer grows on one side, this tail-to-tail coupling is located at the end of the polymer chain. However, if the catalyst walks over the polymer chain and initiates growth on the other side, the tail-to-tail coupling is located somewhere central along the polymer chain. Hence, by determining the relative amount of tail-to-tail couplings at a chain end via ${ }^{1} \mathrm{H}$ NMR analysis, one can determine the amount of bidirectional growth and, consequently, the stickiness $\delta .{ }^{15}$ Using this method, the stickiness is determined for both the polymerization of 2bromo- and 2-chloro- 5-chloromagnesio-3hexylthiophene with $\mathrm{Ni}(\mathrm{dppp}) \mathrm{Cl}_{2}$ and $\mathrm{NiCl}_{2}\left(\mathrm{PPh}_{3}\right) \mathrm{IPr}$ as catalysts. The stickiness for the 
TABLE 1 Influence of the halogen on the stickiness $(\delta)$ during the polymerization

\begin{tabular}{|c|c|c|}
\hline Catalyst & bromo ${ }^{a}$ & chloro $^{b}$ \\
\hline $\mathrm{Ni}(\mathrm{dppp}) \mathrm{Cl}_{2}$ & $0.72 \pm 0.04$ & No unidir. gr. ${ }^{c}$ \\
\hline $\mathrm{NiCl}_{2}\left(\mathrm{PPh}_{3}\right) \mathrm{IPr}$ & $0.66 \pm 0.03$ & $0.52 \pm 0.06$ \\
\hline $\begin{array}{l}\text { apolymerization } \\
\text { hexylthiophene. } \\
\text { chloromagnesio-3-he } \\
\text { assigned since no } \\
\text { log }(0) \text { is an undefine }\end{array}$ & $\begin{array}{l}\text { using 2-bromo-5 } \\
\text { bpolymerization } \\
\text { exylthiophene. } \\
\text { unidirectional growth } \\
\text { ed number. }\end{array}$ & $\begin{array}{l}\text { 5-chloromagnesio-3- } \\
\text { using 2-chloro-5- } \\
\text { value can be } \\
\text { his observed, and }\end{array}$ \\
\hline
\end{tabular}

brominated thiophene monomer in combination with $\mathrm{Ni}(\mathrm{dppp}) \mathrm{Cl}_{2}$ was determined previously by Verswyvel et al. for different chain lengths. ${ }^{15}$ The value is found to remain constant with the chain length, so in this experiment the stickiness was determined for a constant aimed degree of polymerization of 20 units (Table 1, SI).

There is no exact value for the stickiness of the chlorinated monomer polymerized with $\mathrm{Ni}(\mathrm{dppp}) \mathrm{Cl}_{2}$, because no unidirectional growth is observed and the logarithm of zero is not defined. Nevertheless, the influence of changing the halogen is clear: when chlorine is used instead of bromine, the stickiness clearly diminishes for both polymerizations, even to the point where exclusively bidirectional growth is observed for the polymerization with $\mathrm{Ni}(\mathrm{dppp}) \mathrm{Cl}_{2}$. This means that the catalyst is much more likely to "walk" over the chain back and forth, instead of continuing the polymerization at the same chain end. A possible explanation for this observation is a slower oxidative addition $(\mathrm{OA})$, caused by the reduced reactivity of the C$\mathrm{Cl}$ bond with respect to the $\mathrm{C}-\mathrm{Br}$ bond. ${ }^{16-21}$ When there is a larger time gap between the reductive elimination and the $\mathrm{OA}$, the migration of the catalyst along the polymer chain becomes more likely.

Although the stickiness is determined during a homopolymerization, its importance becomes clear during block-copolymerizations with $\mathrm{Ni}(\mathrm{II})$ salts, i.e. without external initiators. When the stickiness is low for the polymerization of the first block, not only $A B$ block-copolymers will be formed. Because the catalyst is likely to walk over the chain and oxidatively insert at the other end, also BAB block-copolymers are synthesized. Consequently, the fraction of $B A B$ blockcopolymers will increase drastically (especially for $\mathrm{Ni}(\mathrm{dppp}) \mathrm{Cl}_{2}$ ) when the halogen is changed from bromine to chlorine. Hence, when only $A B$ block-copolymers are desired, bromosubstituted monomers are the better choice. However, BAB block-copolymers can only be avoided with certainty when external initiators are used.

\section{Rate-determining step}

Since it is likely that the OA becomes slower if a chlorine substituent is used, the question arises whether it becomes the rate-determining step during the polymerization. Important work has been done in this field by the research group of McNeil, who has shown that the transmetallation is the rate-determining step in the polymerization of 2-bromo-5chloromagnesio-3-hexylthiophene with $\mathrm{Ni}(\mathrm{dppp}) \mathrm{Cl}_{2} \cdot{ }^{22,23}$ To verify whether the ratedetermining step changes when the halogen is altered, a ${ }^{31} \mathrm{P}$ NMR measurement is performed during the polymerization of 2-chloro-5chloromagnesio-3-hexylthiophene (SI). If the OA is the rate-determining step, the $\mathrm{Ni}^{0}$-catalyst associated to the polymer chain is the resting state which should be observed with ${ }^{31} \mathrm{P}$ NMR. However, the similarity of our results compared with the ones obtained by Lanni et al. indicate that the transmetallation step is still ratedetermining during this polymerization, while the small difference in peak position can be explained by the presence of $\mathrm{Cl}$ instead of $\mathrm{Br}^{23}$

\section{Effect on thiophene copolymerization}

A random copolymerization is known to be difficult using CTP, and mostly copolymers with similar electronic properties have been synthesized so far. ${ }^{24-29}$ Poly(thiophene) is the benchmark conjugated polymer, so the focus is on investigating the effect of changing the halogen on a copolymerization between two 
different thiophene units, i.e. hexyl- and butylthiophene. These side-chains are chosen because their $\mathrm{CH}_{3}$-signals have a slightly different shift in ${ }^{1} \mathrm{H} N \mathrm{NMR}$, allowing an easy determination of the incorporation of both monomers (SI). Since the difference in electronic properties between both monomers is minimal, the copolymerization is enabled and the effect of changing the halogen becomes clear immediately. The increased electronegativity of $\mathrm{Cl}$ compared to $\mathrm{Br}$ influences the electronic properties of the monomer and can consequently also have an effect on the copolymerization. The chlorine will withdraw more electron density from the monomer, which results in a decreased nucleophilicity of the organomagnesium compound. Copolymers of thiophenes with different sidechains have already been synthesized with KCTP, and -if investigated- these copolymerizations were always found to be random. ${ }^{15,29-32}$ However, to investigate the effect of the halogen on the copolymerization, the randomness of this specific polymerization must also be quantified. Hence, not only the copolymerization between a chloro- and bromo-substituted monomer is analyzed, but also the copolymerization between the two bromo-substituted monomers. Both $\mathrm{Ni}(\mathrm{dppp}) \mathrm{Cl}_{2}$ and $\mathrm{NiCl}_{2}\left(\mathrm{PPh}_{3}\right)$ IPr are used as catalysts (Scheme 2). To quantify the effect of the halogen, the copolymerization parameters were determined using a Lewis-Mayo plot. ${ }^{33}$ To obtain this plot, copolymerizations with different monomer feeds are performed and quenched at low conversion ( $\pm 10 \%)$. At these low conversions, a more substantial incorporation of one of both monomers compared to the monomer feed can be linked to a higher reactivity of this monomer. Once the data points are obtained, a least square fit is performed with the Lewis-Mayo Equation.

$F_{A}=1-F_{B}=\frac{r_{A} f_{A}^{2}+f_{A} f_{B}}{r_{A} f_{A}^{2}+2 f_{A} f_{B}+r_{B} f_{B}^{2}}$

From this fit, $r_{A}$ and $r_{B}$, the reactivity ratios, can be determined. They are defined by the following equations for a copolymerization between monomer $\mathrm{A}$ and $\mathrm{B}$.

$r_{A}=\frac{k_{A A}}{k_{A B}}$

$r_{B}=\frac{k_{B B}}{k_{B A}}$

As can be seen from equation (3) and (4), the reactivity ratios are determined by the ratios of the rate constants for the reaction of a certain chain end $\left(A\right.$ of $B$ ) with itself $\left(k_{A A}\right.$ or $k_{B B}$ ) and with the other monomer $\left(\mathrm{k}_{\mathrm{AB}}\right.$ or $\left.\mathrm{k}_{\mathrm{B}}\right)$. Hence, reactivity ratios close to 1 are observed for a random copolymerization, as there is no preference for one specific monomer to be incorporated.

The Lewis-Mayo plots for the butyl- and hexylthiophene copolymerizations depicted in Scheme 2 are given for $\mathrm{Ni}(\mathrm{dppp}) \mathrm{Cl}_{2}$ in Figure 1, and the data of the least square fit are given in Table 2 for both catalysts. The Lewis-Mayo plot for $\mathrm{NiCl}_{2}\left(\mathrm{PPh}_{3}\right) \operatorname{IPr}$ can be found in $\mathrm{Sl}$, together with more experimental data and procedures.

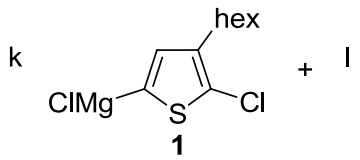

$\mathrm{k}$

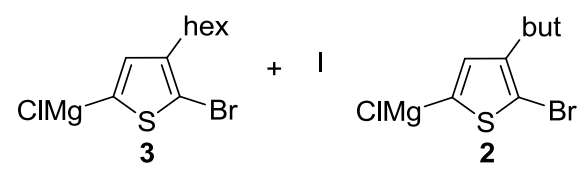

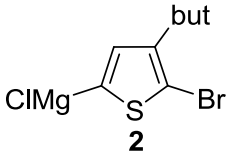
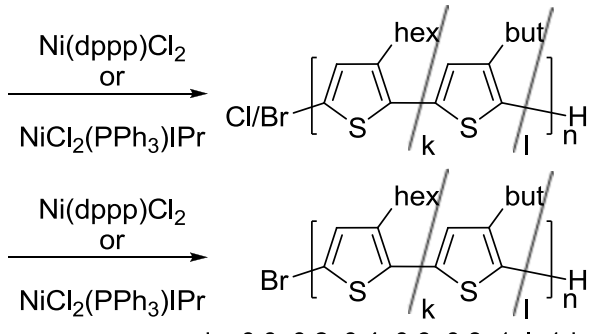

SCHEME 2 Copolymerization of hexyl- and butylthiophene, both with chloro- and bromo-substituted hexylthiophene 


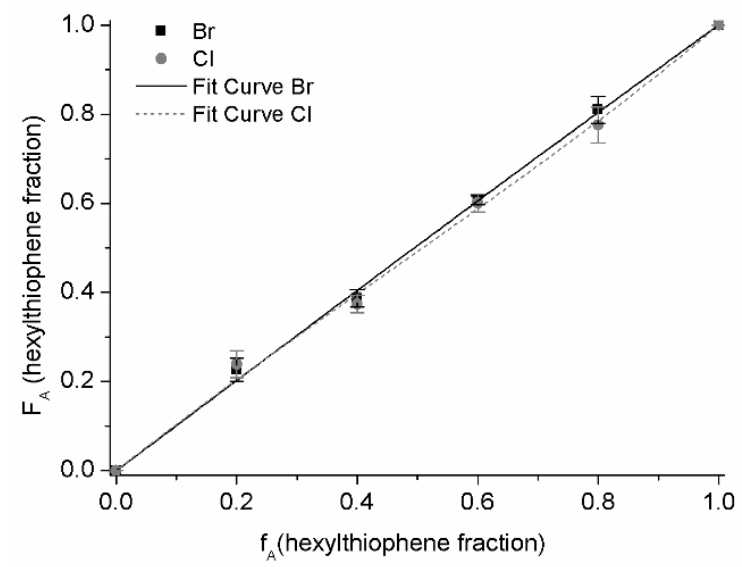

FIGURE 1 Lewis-Mayo plot of the copolymerization of hexyl- and butylthiophene ( $\mathbf{1}$ and $\mathbf{2}(\mathrm{Cl})$ vs $\mathbf{3}$ and $\mathbf{2}(\mathrm{Br})$ ) with $\mathrm{Ni}(\mathrm{dppp}) \mathrm{Cl}_{2}$.

It is clear that a random copolymerization occurs between these two monomers, and that changing the halogen on the hexylthiophene monomer has no significant effect on the copolymerization. Also changing the catalyst from the typically used $\mathrm{Ni}(\mathrm{dppp}) \mathrm{Cl}_{2}$ to $\mathrm{NiCl}_{2}\left(\mathrm{PPh}_{3}\right)$ IPr does not affect the copolymerization behaviour between two thiophene monomers. A small decrease is observed for $r_{A}$ in the copolymerization with the $\mathrm{N}$-heterocyclic carbene ligand, due to a slightly higher incorporation of butylthiophene when $f_{A}=0.8$. The reason for this observation is not known, but it must be noticed that these are the data points with the largest experimental error, and relatively small changes in $\mathrm{F}_{\mathrm{A}}$ already have a large impact on the value for $r_{A}$. Looking at the Lewis-Mayo plot for this copolymerization (SI), one can see that the deviation from the linear 'random copolymer' curve is very limited.
TABLE 2 Copolymerization parameters for the copolymerization between $\mathbf{1}$ and $\mathbf{2} ; \mathbf{3}$ and $\mathbf{2}$.

\begin{tabular}{|c|c|c|c|c|}
\hline & \multicolumn{2}{|c|}{$\mathrm{Ni}(\mathrm{dppp}) \mathrm{Cl}_{2}$} & \multicolumn{2}{|c|}{$\mathrm{NiCl}_{2}\left(\mathrm{PPh}_{3}\right) \mathrm{IPr}$} \\
\hline & $r A^{c}$ & $r^{c}{ }^{c}$ & $r A^{c}$ & $r_{B}{ }^{c}$ \\
\hline Bromo $^{a}$ & $1.0 \pm 0.1$ & $1.0 \pm 0.1$ & $0.7 \pm 0.1$ & $0.9 \pm 0.1$ \\
\hline Chloro $^{b}$ & $1.0 \pm 0.2$ & $0.9 \pm 0.2$ & $0.7 \pm 0.1$ & $1.0 \pm 0.1$ \\
\hline
\end{tabular}

\section{Effect on a thiophene - phenylene copolymerization}

Also the effect of the halogen on a copolymerization between thiophene and phenylene is investigated (Scheme 3). As expected, also changing the halogen to a chlorine atom in a copolymerization of thiophene with 1-bromo-4-chloromagnesio-2,5dioctoxybenzene (4) has no significant effect on the copolymerization. Both for the bromo- and chloro- substituted thiophene monomer, mostly thiophene is incorporated and the amount of phenylene monomer in the polymer is far below the aimed $50 \%$. However, it must be noticed that this quantity increases remarkably when the $\mathrm{NiCl}_{2}\left(\mathrm{PPh}_{3}\right) \mathrm{IPr}$ catalyst is used in the copolymerization, for $\mathbf{1}$ as well as $\mathbf{3}$, going from $10-15 \%$ to over $30 \%$. Hence, although the effect of the halogen is limited, an interesting class of catalysts for (random) copolymerizations in KCTP is discovered. The class of $\mathrm{N}$-heterocyclic carbene catalysts can be of interest when a CTP copolymerization of two electronically distinct monomers is desired and should be investigated further. ${ }^{34-37}$
0.5

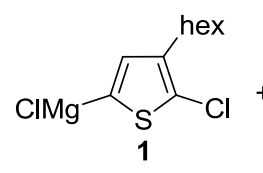

$+0.5$<smiles>CCOc1cc(C)c(OC(C)C)cc1Br</smiles>

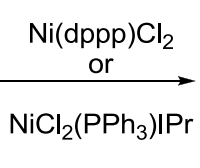

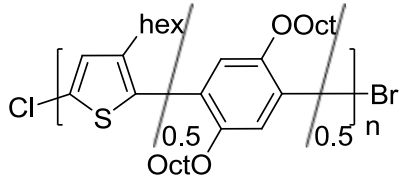

$k=0.0,0.2,0.4,0.6,0.8,1 ; l=1-k$

SCHEME 3 Copolymerization of 2-chloro-5-chloromagnesio-3-hexylthiophene (1) 1-bromo-4chloromagnesio-2,5-dioctoxybenzene (4). For reference purposes, this polymerization was also performed with 2-chloro-5-chloromagnesio-3-hexylthiophene (3). 


\section{Effect of changing the organometallic function}

Especially in copolymerizations, changing the organometallic function of one of the monomers can be an interesting tool to tune reactivity ratios and, hence, the molecular structure of the copolymer. While organomagnesium compounds are by far the most popular in a KCTP polymerization, also organozinc compounds can result in a controlled polymerization. This was already evidenced for P3AT, which is why we will focus on a poly(thiophene) copolymerization. The lower reactivity of an organozinc compound could result in the formation of a gradient copolymer from the otherwise randomly copolymerized hexyl- and butylthiophene (as shown in the first part of this article). Since it is known that the transmetallation is the ratedetermining step in the KCTP polymerization with $\mathrm{Ni}(\mathrm{dppp}) \mathrm{Cl}_{2}$, and changing the organometallic function will affect this step in the polymerization, our focus lies with this catalyst. In this case, a slightly different approach was used, where hexyl- and butylthiophene were copolymerized in a 50/50 ratio 4 times: with $\mathrm{MgCl}$ on both monomers, $\mathrm{ZnCl}$ on both monomers, $\mathrm{MgCl}$ on butylthiophene and $\mathrm{ZnCl}$ on hexylthiophene and vice versa (Scheme 4). After quenching at low conversion, the effect of the organometallic function can be investigated. Despite the clearly slower polymerization kinetics (the solution turns red far more slowly), no effect of using $\mathrm{ZnCl}$ was observed. For all combinations of the organometallic functions, the ratio of both monomers in the copolymer at low conversion was found to be 50/50 (SI). Because organozinc compounds are known to be less reactive, the reason behind this lack of effect was investigated. To test the hypothesis that the organometallic functions are exchanged between the monomers during mixing, a new experiment was designed (Scheme 5). The nucleophilic addition of a Grignard reagent on a carbonyl function is a well-known reaction which cannot be performed with an organozinc compound. Consequently, if $\mathbf{3}$ and $\mathbf{5}$ are mixed with benzaldehyde, one would expect to form only a coupled product with the organomagnesium compound 3. However, it was observed that both $\mathbf{6}$ and $\mathbf{7}$ were obtained (SI), despite the fact that organozinc compound $\mathbf{5}$ is not reactive enough for this type of coupling reactions. As a consequence, it was concluded that the organometallic functions of both monomers are interchanged. Furthermore, this is a rapid process, since the monomers are only mixed for 5 minutes before addition and the coupled products are found in a 50/50 ratio. Obviously, this explains why the use of different organometallic functions showed no effect in the copolymerization.

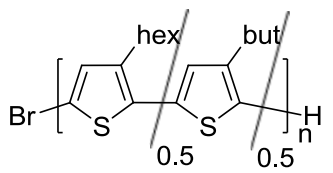

SCHEME 4 Hexyl- and butylthiophene copolymerization to investigate the effect of changing the

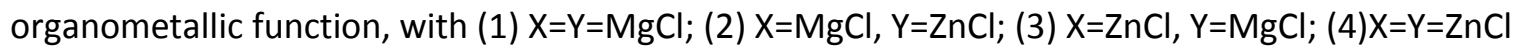

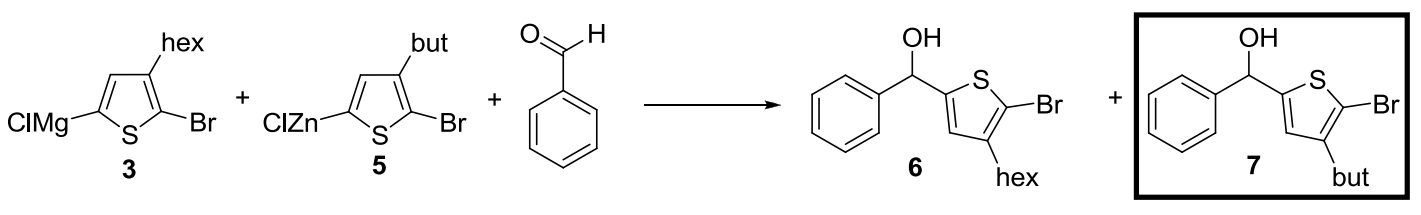

SCHEME 5 Experiment to test whether the organometallic function is exchanged during mixing of $\mathbf{3}$ and 5. Since not only 6 , but also 7 is recovered after reaction, it is concluded that the exchange occurs. 
To counter this problem, two different strategies were considered. First, the solution was cooled to $0^{\circ} \mathrm{C}$ to slow down the exchange. However, this proved to be ineffective. Because Hevia et al. found that mixed magnesium-zinc compounds are formed when both are combined, four extra equivalents of $\mathrm{LiCl}$ were added to the reagents in a next attempt. ${ }^{38}$ If the exchange of the organometallic functions would proceed via the formation of a dimeric complex, the $\mathrm{LiCl}$ should be able to counter this problem. It is known that $\mathrm{LiCl}$ breaks up aggregates of Grignard reagents and forms 'ate'-complexes, which do not aggregate because of their charge. ${ }^{39,40}$ However, this also did not resolve the problem, leaving the mechanism for this exchange unresolved.

\section{CONCLUSIONS}

Changing the halogen on a thiophene monomer in a KCTP polymerization from the regularly used bromine to a chlorine atom, drastically lowers the stickiness of the catalyst during the homopolymerization. Although a slower oxidative addition because of the stronger $\mathrm{C}-\mathrm{Cl}$ bond is a plausible explanation for this observation, it is not slowed down to the extent that it becomes the rate-determining step. This is still the transmetallation in a polymerization with $\mathrm{Ni}(\mathrm{dppp}) \mathrm{Cl}_{2}$. In a copolymerization with other-brominated- thiophene monomer, the change of halogen has no effect on the copolymerization behavior. Hence, in most cases bromo- and chloro-substituted monomers can be interchanged, but careful consideration is required during a block-copolymerization with a $\mathrm{Ni}(\mathrm{II})$-salt. Because of the lower stickiness of the chloro-substituted monomer, the fraction of BAB block-copolymers will be higher. Second, it is observed that $\mathrm{NiCl}_{2}\left(\mathrm{PPh}_{3}\right)$ IPr provides a better copolymerization between thiophene and phenylene. Consequently, N-heterocyclic carbene ligands are an interesting class of ligands for random copolymerizations of electronically distinct monomers and further research is required. Also in this case, the copolymerization behavior of the brominated and chlorinated thiophene monomer is very similar. The idea of altering the reactivity ratio of monomers in a copolymerization by changing the organometallic function of one of the monomers from a chloromagnesio to a chlorozincio substituent, could not be further exploited. The reason is that these organometallic functions exchange during the mixing of the monomer. As a consequence, the polymer composition is not altered.

\section{ACKNOWLEDGEMENTS}

We are grateful to the Onderzoeksfonds K.U.Leuven/Research Fund K.U.Leuven and the Fund for Scientific Research (FWO-Vlaanderen) for financial support. T.H. is a doctoral fellow of the Fund for Scientific Research (FWOVlaanderen). Pieter Leysen is acknowledged for performing the GC-MS measurements.

\section{REFERENCES AND NOTES}

1 E. E. Sheina, J. Liu, M. C. lovu, D. W. Laird and R. D. McCullough, Macromolecules, 2004, 37, 3526-3528.

2 A. Yokoyama, R. Miyakoshi and T. Yokozawa, Macromolecules, 2004, 37, 1169-1171.

3 R. Miyakoshi, K. Shimono, A. Yokoyama and T. Yokozawa, J. Am. Chem. Soc., 2006, 128, 16012-16013.

$4 \quad$ A. Sui, X. Shi, S. Wu, H. Tian, Y. Geng and F. Wang, Macromolecules, 2012, 45, 5436-5443.

$5 \quad$ P. Willot, D. Moerman, P. Leclère, R. Lazzaroni, Y. Baeten, M. Van der Auweraer and G. Koeckelberghs, Macromolecules, 2014, 47, 6671-6678.

6 C. R. Bridges, T. M. McCormick, G. L. Gibson, J. Hollinger and D. S. Seferos, J. Am. Chem. Soc., 2013, 135, 13212-9. 
M. Heeney, W. Zhang, D. J. Crouch, M. L. Chabinyc, S. Gordeyev, R. Hamilton, S. J. Higgins, I. McCulloch, P. J. Skabara, D. Sparrowe and S. Tierney, Chem. Commun. (Camb)., 2007, 47, 5061-5063.

A. Yokoyama, A. Kato, R. Miyakoshi and T. Yokozawa, Macromolecules, 2008, 41, 7271-7273.

9 F. Pammer, J. Ja, B. Rudolf and Y. Sun, Macromolecules, 2014, 47, 5904-5912.

M. C. Stefan, A. E. Javier, I. Osaka and R. D. McCullough, Macromolecules, 2009, 42, 30-32.

S. Tamba, K. Shono, A. Sugie and A. Mori, J. Am. Chem. Soc., 2011, 133, 97009703.

12 T. Higashihara and E. Goto, Polym J, 2014, 46, 381-390.

T. Higashihara, E. Goto and M. Ueda, ACS Macro Lett., 2012, 1, 167-170.

R. Tkachov, V. Senkovskyy, H. Komber, J. U. Sommer and A. Kiriy, J. Am. Chem. Soc., 2010, 132, 7803-7810.
M. Verswyvel, F. Monnaie and G.

Koeckelberghs, Macromolecules, 2011, 44, 9489-9498.

J. Berding, M. Lutz, A. L. Spek and E. Bouwman, Organometallics, 2009, 28, 1845-1854.

\section{Zhang and Z.-X. Wang, Organometallics, 2009, 28, 6507-6514.}

R. Ghosh and A. Sarkar, J. Org. Chem., 2010, 75, 8283-6.

Z. Xi, B. Liu and W. Chen, J. Org. Chem., 2008, 73, 3954-7.

P. Walla and C. O. Kappe, Chem. Commun. (Camb)., 2004, 564-5.
N. Liu, L. Wang and Z.-X. Wang, Chem. Commun., 2011, 47, 1598-1600.

E. L. Lanni and A. J. McNeil, J. Am. Chem. Soc., 2009, 131, 16573-16579.

E. L. Lanni and A. J. McNeil, Macromolecules, 2010, 43, 8039-8044.

24 T. Hardeman and G. Koeckelberghs, Macromolecules, 2015, 48, 6987-6993.

25 J. Hollinger, J. Sun, D. Gao, D. Karl and D. S. Seferos, Macromol. Rapid Commun., 2013, 34, 437-441.

E. F. Palermo and A. J. McNeil, Macromolecules, 2012, 45, 5948-5955.

27 T. Hardeman and G. Koeckelberghs, Macromolecules, 2014, 47, 8618-8624.

28 H. Bronstein, M. Hurhangee, E. C. Fregoso, D. Beatrup, Y. W. Soon, Z. Huang, A. Hadipour, P. S. Tuladhar, S. Rossbauer, E. Sohn, S. Shoaee, S. D. Dimitrov, J. M. Frost, R. S. Ashraf, T. Kirchartz, S. E. Watkins, K. Song, T. Anthopoulos, J. Nelson, B. P. Rand, J. R. Durrant and I. McCulloch, Chem. Mater., 2013, 25, 4239-4249.

29 J. R. Locke and A. J. McNeil, Macromolecules, 2010, 43, 8709-8710.

E. F. Palermo, H. L. van der Laan and A. J. McNeil, Polym. Chem., 2013, 4, 46064611.

31 K. Buga, R. Pokrop, M. Zagórska, R. Demadrille and F. Genoud, Synth. Met., 2005, 153, 137-140.

P.-T. Wu, G. Ren and S. A. Jenekhe, Macromolecules, 2010, 43, 3306-3313.

F. R. Mayo and F. M. Lewis, J. Am. Chem. Soc., 1944, 66, 1594-1601.
K. Matsubara, K. Ueno and Y. Shibata, Organometallics, 2006, 25, 3422-3427. 
35 K. Matsubara, S. Miyazaki, Y. Koga, Y. Nibu and T. Hashimura, Organomet. Chem., 2008, 4184- 4186.

36 A. Mori, M. Fujio and S. Tamba, Heterocycles, 2015, 90, 617-624.

37 W. a. Herrmann and C. Köcher, Angew. Chemie Int. Ed. English, 1997, 36, 21622187.
38 E. Hevia, J. Z. Chua, P. García-Alvarez, A. R. Kennedy and M. D. McCall, Proc. Natl. Acad. Sci. U. S. A., 2010, 107, 5294-9.

39 J. P. Lamps and J. M. Catala, Macromolecules, 2011, 44, 7962-7968.

40 A. Krasovskiy and P. Knochel, Angew. Chem. Int. Ed. Engl., 2004, 43, 3333-6. 


\section{GRAPHICAL ABSTRACT}

Tine Hardeman, Jasmine De Becker, Guy Koeckelberghs

Influence of the Halogen and Organometallic Function in a KCTP (co)polymerization

The influence of changing the halogen and the organometallic function on thiophene monomer in a Kumada Catalyst Transfer Polycondensation is investigated. The stickiness is reduced when a chlorine substituent is used instead of the more common bromine. The change of halogen has no effect on the behavior in copolymerizations. When two thiophene monomers -one organomagnesium and one organozinc compound- are copolymerized, the organometallic functions interchange. Resultantly, the molecular structure of the polymer is not altered.

- $=\mathrm{Ni}(\mathrm{dppp}) \mathrm{Cl}_{2}, \mathrm{NiCl}_{2}\left(\mathrm{PPh}_{3}\right) / \mathrm{Pr}$

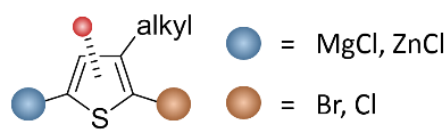

Influence on KCTP (co)polymerization 